\title{
Out on their own: a test of adult-assisted dispersal in fledgling brood parasites reveals solitary departures from hosts
}

Matthew I. M. Louder ${ }^{1,2^{*}}$, Michael P. Ward ${ }^{1,2}$, Wendy M. Schelsky ${ }^{2}$, Mark E. Hauber ${ }^{3}$, Jeffrey P. Hoover ${ }^{2}$

${ }^{1}$ Department of Natural Resources and Environmental Sciences, University of Illinois at UrbanaChampaign

${ }^{2}$ Illinois Natural History Survey, Prairie Research Institute, University of Illinois at Urbana-Champaign

${ }^{3}$ Department of Psychology, Hunter College and the Graduate Center of the City University of New York

*Current address: Department of Biology, East Carolina University. Correspondence:

mckimlouder@gmail.com 
1 Title: Out on their own: a test of adult-assisted dispersal in fledgling brood parasites reveals

2 solitary departures from hosts

3 ABSTRACT

4 Brood parasitic offspring sexually (mis)imprinting on the foster parents is considered one of the

5 greatest constraints to the evolution of interspecific avian brood parasitism. While most non-parasitic

6 juvenile birds learn the behaviours and mate choice preferences from their own parents, social parasites

7 must avoid misimprinting on their host species' phenotype in order to accurately recognize conspecifics.

8 One mechanism to assure accurate species recognition by juvenile parasites is to begin to associate with

9 adult parasitic conspecifics, known as the 'first contact' scenario, whereby adult female parasites facilitate

10 the dispersal of their offspring away from hosts, thus providing accurate referents for conspecific

11 recognition. Using an automated radio telemetry system, we determined the presence or absence (every 1-

122 minutes during 3 breeding seasons; 516315 search occasions) of radio-tagged parasitic adult female

13 brown-headed cowbirds (Molothrus ater), and compared their departures from a forest study site with

14 those of genetic offspring or experimentally transplanted (non-related) juvenile cowbirds within the

15 female's egg-laying range. Contrary to our predictions, we found no support for the facilitation of

16 juvenile cowbird dispersal by adult female cowbirds. Juvenile cowbirds typically were not located within

17 their mother's home range when departing the forest and, likewise, departure events for neither natal nor

18 experimentally transplanted juveniles $(<2 \%)$ overlapped temporally with the departure of the genetically

19 assigned mother or other, local radio-tagged female cowbirds. Surprisingly, we found that juvenile

20 cowbirds primarily depart from the host's territory at sunset, when adult female cowbirds are infrequently

21 present within the forest. Our results suggest that a solitary nocturnal roosting behaviour of juvenile

22 cowbirds may facilitate independence from their hosts, thus minimizing the risk of misimprinting on

23 heterospecific phenotypes. This strategy may also indirectly promote conspecific interactions, providing

24 further evidence for the importance of host- and conspecific independent social preferences in the

25 evolution of avian brood parasitism. 
Interspecific avian brood parasites exploit the parental care of host species and avoid the energetic demands of raising offspring by laying their eggs in host species' nests. Obligate brood parasitism has served as a 'model system' influencing our understanding of both the coevolutionary process (Feeney, Welbergen, \& Langmore, 2014; Rothstein, 1990; Soler, 2014) and the social recognition systems (Göth \& Hauber, 2004) of hosts and parasites. Similarly, with opportunities to readily quantify the costs and benefits of this intriguing form of reproduction, avian host-parasite systems provide an opportunity to understand some constraints on the evolution of life-history strategies, including parental investment (Kruger, 2007).

Obligate avian brood parasitism has proven to be a persistent reproductive strategy, having evolved independently at least seven times from non-parasitic, parental ancestors (Rothstein, 1990; YomTov \& Geffen, 2006). Yet brood parasitism is rare ( $1 \%$ of all bird species) (Payne, 1977), likely reflecting the complications that arise during the initial evolution of interspecific brood parasitic behaviours. In nearly every test where the offspring of two bird parental species are switched early in the nestling phase, cross-fostered juveniles learn the behaviours and mate-choice decisions of their foster species (i.e. sexual imprinting: ten Cate \& Vos, 1999); including facultative interspecific parasites: (Sorenson, Hauber, \& Derrickson, 2010). While sexual imprinting has significant implications for speciation by influencing the process of the recognition of suitable mates in many sexually reproducing species (Irwin \& Price, 1999; Laland, 1994), including African brood parasites (Payne, Payne, Woods, \& Sorenson, 2000), sexual imprinting is conversely one of the greatest constraints on the evolution of brood parasitism (Davies, 2000; Slagsvold \& Hansen, 2001; Sorenson et al., 2010). This leads to the question of how juvenile brood parasites avoid sexually misimprinting on their host species (Hauber, Russo, \& Sherman, 2001).

Misimprinting would result in hybridization between hosts and parasites; however, hybridization is rarely documented within the $\sim 100$ species of extant obligate brood parasites (e.g. Payne \& Sorenson, 2004). While genetically based preferences for conspecific phenotypes likely guide species recognition, 
learning strongly contributes to recognition systems in both parasitic and non-parasitic bird species

54 (Hauber et al., 2001; Payne et al., 2000; Price, 2008). When raised in isolation, the obligate brood

55 parasitic brown-headed cowbird (Molothrus ater) will respond with copulatory displays to conspecific

56 songs (King \& West, 1977) and even as nestlings will increase begging in response to conspecific calls

57 (Hauber et al., 2001), indicating the earliest onset of conspecific recognition capabilities. Yet by

58 experimentally extending social contact with heterospecific species in aviaries, both male cowbirds and

59 Redheads (Aythya Americana; a facultative interspecific parasitic duck), preferred to sexually display to

60 their hosts over conspecifics (Freeberg, King, \& West, 1995; Sorenson et al., 2010). Thus, laboratory

61 experimentation has revealed a species recognition paradox, whereby brood parasites incorporate learned

62 phenotypic components for conspecific recognition and mate choice, in spite of being raised by

63 inappropriate referents (i.e. their host species) (Göth \& Hauber, 2004). However, by spatially segregating

64 from the host prior to critical periods for song learning and mate choice, typical in the development of

65 young songbirds (Bateson, 1979; Brainard \& Doupe, 2002; Hensch, 2004), juvenile brood parasites could

66 avoid sexually imprinting on their host. Here we set out to test this hypothesis of early spatial segregation

67 from the host by juveniles of an obligate brood parasite.

Adult brood parasites are generally thought to relinquish all forms of parental care after laying their eggs, but adult parasites could influence the dispersal of their offspring away from their hosts ('first contact' hypothesis; Hauber, 2002). The guidance of juvenile brood parasites away from hosts would not

71 only reduce the chance of misimprinting, but the interaction with the adult cowbird would directly

72 provide salient conspecific songs and behaviours suitable for appropriate sexual imprinting and survival.

73 Female-assisted dispersal of offspring provides a mechanism to explain why Hahn and Fleischer (1995)

74 reported $36 \%$ of female-juvenile cowbird pairs captured while feeding together were closely related.

75 Similarly, some evidence indicates that juvenile brood parasitic great spotted cuckoos (Clamator

76 glandarius) potentially learn to recognize conspecifics by imprinting on adult cuckoos that have

77 maintained contact throughout the nestling and fledgling period (Soler \& Soler, 1999). Adult female

78 brood parasites may have played an important role in the evolution of brood parasitism by facilitating 
post-fledging dispersal and initiating species recognition in their own offspring, thereby circumventing the constraint of sexually imprinting on the host species (Hauber \& Dearborn, 2003). Critically, the

81 juvenile parasitic spatial segregation from hosts and the conspecifically assisted avoidance of sexual

82 misimprinting hypotheses make specific predictions about the social developmental trajectory of brood

83 parasitic young, which can be tested by extensively tracking the location of juvenile and adult parasites in 84 space and time.

We employed an automated radio telemetry system (ARTS), where the study site occupancy of

86 female brown-headed cowbirds and their offspring could be estimated every 1-2 minutes, to investigate

87 whether adult females facilitate the departure of juvenile cowbirds from their hosts. Adult female

88 cowbirds approach conspecific juveniles in the laboratory and conspecific calls broadcasted in the wild,

89 over heterospecifics (Hauber, 2002) and likewise, juvenile cowbirds prefer to spatially associate with

90 adult conspecific female calls over heterospecifics in laboratory (Hauber 2002) and field choice trials

91 (Hauber et al., 2001), providing support for the hypothesis of female-assisted departure of their offspring.

92 Adult female cowbirds are typically spatially faithful to a breeding area throughout the season (Dufty,

93 1982; Hahn, Sedgwick, Painter, \& Casna, 1999; Hauber, Strausberger, Feldheim, Lock, \& Cassey, 2012;

94 Raim, 2000; Rivers et al., 2012), and monitor the content of recently parasitized nests (Hoover \&

95 Robinson 2007), further presenting female cowbirds with the opportunity to facilitate the necessary

96 dispersal of juvenile cowbirds. We predicted that (i) juvenile cowbirds are located within their mother's

97 home-range when juveniles depart from their host, and (ii) juvenile departures should coincide with the

98 mother's movement away from the host. We further predicted that departure events of juvenile cowbirds

99 experimentally transplanted within a different female's home range would correlate with the departure

100 times of the local female, suggestive of conspecific bias in juvenile cowbirds' following behaviours. We

101 also investigated general patterns of juvenile departure events and female study site occupancy to

102 determine if juvenile dispersal is guided by non-related females.

\section{METHODS}

\section{Species and study system}


We studied the movements of brown-headed cowbirds during four breeding seasons within a long-term (20+ years) nest box study system located within the Cache River watershed, southern Illinois

107 USA; which supports investigations of the host-parasite interactions between prothonotary warblers

108 (Protonotaria citrea) and cowbirds (e.g. Hoover, 2003). The prothonotary warbler, a Neotropical 109 migratory songbird that breeds in bottomland swamps throughout the southeastern USA, is the only 110 species regularly parasitized by brown-headed cowbirds that will nest in artificial nest boxes (Petit, 1999).

111 Adult brown-headed cowbirds forage socially in pastures and agriculture, and female cowbirds

112 subsequently parasitize the songbirds within the surrounding landscape (Thompson, 1994), particularly 113 forests (Hahn \& Hatfield, 1995).

The warblers are able to successfully raise cowbird nestlings (Hoover 2003), and their nest boxes are commonly parasitized ( 70\%; Hoover \& Hauber, 2007; Hoover, Yasukawa, \& Hauber, 2006). We placed nest boxes 50-100m apart within suitable habitat on greased conduit poles, and upon hatching,

117 surrounded the nest box with wire to eliminate the chance for nest predation. To reduce the effects of nest ectoparasites, such as bird blowfly maggots (Protocalliphora spp.) on nestling and fledgling survival (e.g.

119 (Streby, Peterson, \& Kapfer, 2009), we replaced the nesting material every 3-5 days with Spanish moss 120 after hatching. Each active nest box was checked every 1-2 days during the egg laying stage and then 121 monitored every 3-5 days until fledging. Most cowbird chicks are raised in the absence of conspecifics 122 (Hauber, 2001; Lowther, 1993); however, occasionally more than one cowbird are raised in a brood (e.g. 123 Rivers et al. 2012; Hoover, 2003; McLaren et al. 2003). Being raised with cowbird nestmates could 124 theoretically impact the recognition system (Soler \& Soler, 1999), therefore, we limited each parasitized 125 nest to a single cowbird nestling (labeled "natal" nest box/chick hereafter). We experimentally added a 126 single cowbird nestling (labeled "transplanted" hereafter), collected from outside of the study sites $>1$ $127 \mathrm{~km}$, to non-parasitized warbler nests and parasitized nests that failed to hatch cowbird offspring. In 128 multiply-parasitized nests where $>1$ cowbird nestling hatched, additional cowbird nestlings (1-4 days 129 post-hatching) were moved to a nest box on a different study site with appropriately aged non-parasitized 130 nests or where cowbird eggs failed to hatch. 


\section{Radio telemetry}

During 2011-2014, we captured adult female cowbirds within the study sites by broadcasting

133 cowbird calls adjacent to a mist net or by inserting trap doors within active warbler nest boxes prior to

134 cowbird egg laying in the early morning (1 hour before sunrise); trap doors were then removed after

135 cowbird capture and prior to warbler egg laying. Adult female cowbirds were captured during the first

136 weeks of egg-laying within our study site, and prior to the fledging of the juveniles. We attached radio-

137 transmitters to adult female and juvenile cowbirds (transmitter mass $=1.6$ and $0.9 \mathrm{~g}$, respectively; $<5 \%$

138 body mass) within two distinct study sites ( $\mathrm{ABC}$ and $\mathrm{HB}$, separated by $\sim 1$ km; Fig. 1).

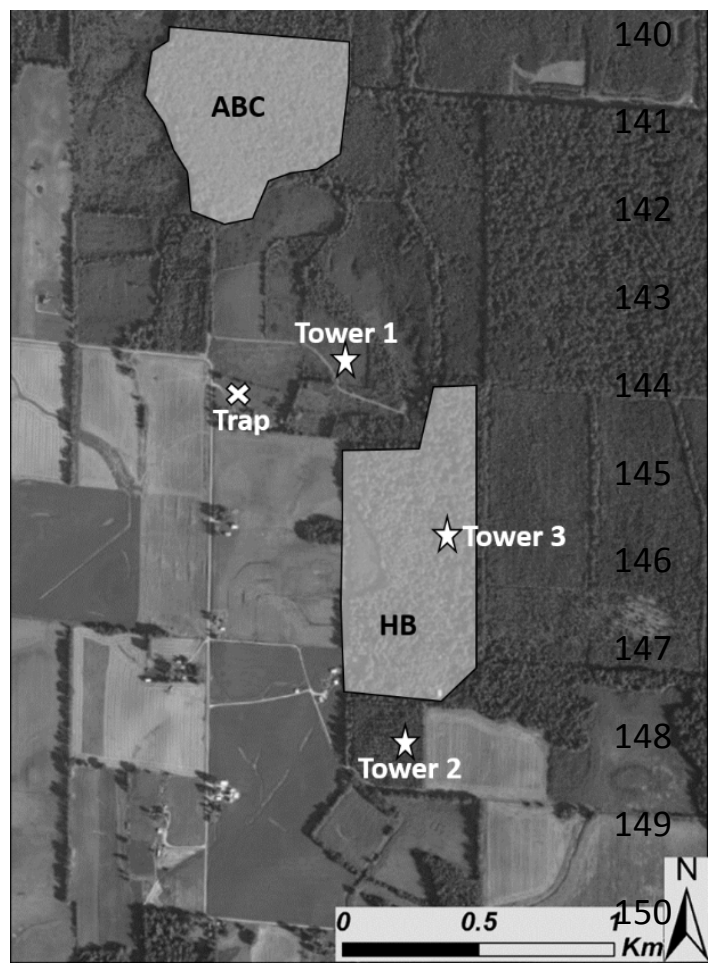

Figure 1 . The study system depicting the locations

of each nest box study site (ABC and $\mathrm{HB}$; gray polygons),

the automated radio telemetry system (ARTS) towers

(stars), the baited fly-in trap (denoted by an X). The study

site HB is within the ARTS coverage.

Using the figure-8 harness method (Rappole \& Tipton, 1991), we affixed transmitters to the

cowbird's lower back connected to elastic nylon beading cord looped around each thigh. Harnesses were

152 made in advance to minimize handling time, and nylon was chosen as it deteriorates over time and will

153 fall off the individual ( 3-6 months; Streby et al. 2015). We attached transmitters to juvenile cowbirds on

154 the morning of post-hatch day 10, the mean age of fledging (Woodward, 1983). Using a handheld 3-

155 element Yagi antennae and receiver, we searched for each cowbird within the study sites throughout the

156 transmitter lifespan (adult transmitter $=\sim 12$ weeks; juvenile transmitter $=3-5$ weeks; Holohil Systems 
Ltd., Ontario, Canada; JDJC Corp., Fisher, IL, USA), or until the cowbird was not detected for 5 days.

We identified locations for radio-tagged individuals within the forest by visual detection, or when not observed due to dense vegetation, we inferred the location based on the strength of the telemetry signal at several angles from the suspected location. We did not detect any additional noticeable stress or mortality caused by radio telemetry on juveniles or adult females. Locations determined by radio-tracking were recorded using a handheld global positioning system receiver (GPS 3, Garmin, Olathe, KS, USA). We estimated the distance $(\mathrm{m})$ each juvenile cowbird location was from their fledging nest box (Euclidean 164 straight-line). Radio-telemetry and sampling of brown-headed cowbirds was approved by the University of Illinois Institutional Animal Care and Use Committee (Permit Numbers: 09107, 12079, and 12080), the U.S. Fish and Wildlife Service (Permit Number: MB815400-0), and the U.S. Geological Survey (Banding Permit Number: 06507).

We liberally estimated forest home-ranges for female cowbirds based on $100 \%$ minimum convex polygons (MCP), the smallest polygon that encompasses all recorded radio-tracked locations for each female within the forest for a given year. As opposed to home-range estimation techniques such as kernel estimators, MCPs have the tendency to overestimate home-range size (Powell, 2000), because the

172 polygon likely includes areas seldom used by the animal. However, we think that MCPs provides the best 173 test of our hypothesis for the potential area of overlap where juveniles have the greatest potential to 174 encounter the female cowbird in question. If, in turn, our hypothesis is not supported, we provide a very 175 conservative test.

\section{Automated radio telemetry system}

To estimate the timing of adult and juvenile cowbird's occupancy and departure from the study 178 sites, we deployed an automated radio telemetry system in 2012 (ARTS; Kays et al., 2011; M. P. Ward, 179 Alessi, Benson, \& Chiavacci, 2014; M. P. Ward, Sperry, \& Weatherhead, 2013). We placed three towers 180 adjacent to one study site (HB; Fig. 1): two tall towers $(18 \mathrm{~m})$ placed to the north/south borders and one 181 short tower $(5 \mathrm{~m})$ positioned within the study site. Each tower holds six directional antennas spaced by $18260^{\circ}$ to give $360^{\circ}$ coverage and an automated recording unit (ARU; JDJC Corp. Fisher, IL, USA), which 

individual was considered present within the forest if the signal strength was greater than $-130 \mathrm{dBM}$ for any south antennas $\left(120^{\circ}\right.$ and $\left.180^{\circ}\right)$ for tower 1 , north antennas $\left(0^{\circ}, 60^{\circ}\right.$ and $\left.300^{\circ}\right)$ for tower 2 and any antenna on tower 3. This signal strength threshold was derived from comparisons of signal strength of juveniles and adults when known to occur within the forest from hand-tracked observations. This threshold was also considered conservative in that relatively weak transmitter signals detected by the ARTS, either from individuals sitting on the ground or short-distance departures, would be considered present within the forest under this criterion. To account for electromagnetic noise, which can obscure occupancy data from apparent signals that appear to be from the radio transmitter, we estimated noise by measuring the signal strength between transmitter pulses and dismissed the data when noise was greater than $-130 \mathrm{dBM}$.

We pooled binomial (yes/no) occupancy data into 30-minute intervals for analysis, and individuals were considered present within the forest if detected $>2$ times during a given interval. We assumed the individual departed the forest if not detected in the subsequent 30-minute interval. In other words, we classified departure events when individuals transitioned from present to absent for at least 30minutes. Intervals with $<3$ observations, typically due to electromagnetic noise from lighting, were removed from the analysis. For analysis and presentation, we grouped time observations into distinct groups: sunrise $=1.5$ hour buffer around sunrise (4:00-7:00); morning $=7: 00-12: 00$; afternoon $=12: 00$ $18: 30$; sunset $=1.5$ hour buffer around sunset $(18: 30-21: 30)$; night $=21: 30-4: 00$. To determine the reliability of ARU-detected occurrence and departure events, we compared the presence/absence data with known occurrences within the forest determined by hand-tracked locations.

\section{Maternity analysis}

To determine maternity of natal and transplanted radio-tracked juveniles, we collected blood samples with sterile needles $(\sim 50 \mu \mathrm{L})$ from the brachial vein of juvenile and adult cowbirds, both males and females captured within the forest and at a feeder trap (see below), and stored in lysis buffer at 
ambient temperatures or at $4^{\circ} \mathrm{C}$. We used DNeasy Blood and Tissue kit (Qiagen, Valencia, CA, USA) to

210 extract DNA from all blood samples. We did not observe any significant harm (e.g. infection, excessive

211 clotting) caused by the collection of blood samples. We used nine microsatellite primer pairs for

212 genotyping and followed PCR amplification described in previous studies: three loci (CB 1, CB 12, and

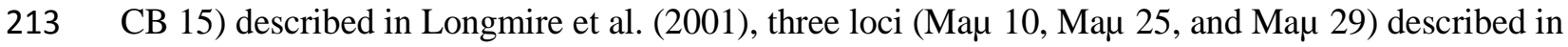

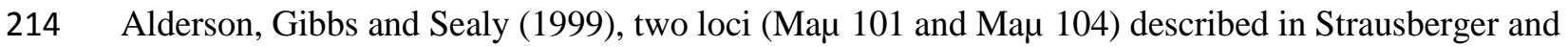

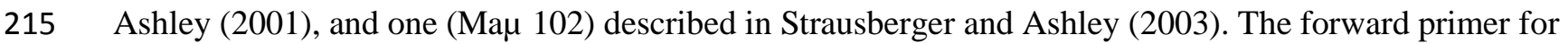

216 each locus was fluorescently labeled (6-FAM, HEX, or NED) and analyzed on an AB 3730xl DNA

217 analyzer (Biotechnology center, University of Illinois, Urbana, IL, USA) to determine fragment sizes.

218 Genotypes were assigned, both manually and automatically, using GeneMapper 3.7 (Applied Biosystems,

219 Foster City, CA, USA).

Deviations from Hardy-Weinberg equilibrium (HWE) of the 9 microsatellite loci were tested

221 using Genepop'007 (Rousset, 2008). For maternity analysis, we used a likelihood-based approach

222 implemented in CERVUS 3.0 (Kalinowski, Taper, \& Marshall, 2007) to assign genotyped mothers to

223 their putative offspring. Because parentage assignment from program CERVUS depends largely on the

224 genetic variability of the loci used and their resulting power to exclude potential parents, we attempted to

225 increase the accuracy of allele frequencies for the study population by including the genotypes of male

226 and female cowbirds captured at a feeder trap in addition to the adults captured within the study sites. The

227 fly-in trap, located $\sim 1 \mathrm{~km}$ from the study sites (Fig. 1), was baited with a corn-sunflower seed mixture

228 and watched continually during trapping attempts. To determine the statistical confidence of maternity

229 assignments, we performed a simulation of 10000 tests based on observed genotype frequencies,

230 assuming $90 \%$ of candidate mothers were sampled, a breeding population of 20 adult females among the

231 study sites and 0.01 error rate for all loci. Mother identity to radio-tagged juveniles was assigned with $\geq$

$23295 \%$ confidence, as determined by the likelihood-odds ratios (Kalinowski et al., 2007).

\section{Statistical analyses}



from the natal or transplanted box was influenced by post-fledging age. To determine if the duration of time spent out of the forest after a departure event varies throughout the day, we used a LMM and

237 included time intervals (sunrise, morning, afternoon, sunset and night) as an explanatory variable and the

238 time after departure as the response variable. Because the duration of time and distance tended to be right-

239 skewed, we used an exponential response distribution; results were qualitatively similar when compared 240 to log-transformed response variables. For binary response variables, we used generalized linear mixed 241 models (GLMM) with a binomial response, logit link function, and Laplace likelihood approximation 242 (Bolker et al., 2009). We included whether the juvenile hand-tracked location was inside the respective 243 female's home range (binomial response variable) with post-fledging age as an explanatory variable. To analyze the probability of juvenile departure (binomial response) we included time intervals. Similarly, we included time intervals as an explanatory variable to predict the probability of forest occupancy for adult females (binomial response). We included only those juveniles that were continually located for

247 more than 10 days post-fledging, assuming that cowbirds disperse from their natal site 20-30 days after 248 fledging (Woodward, 1983). Juvenile models included whether or not the individual was transplanted 249 (categorical) as an explanatory variable. Our data only include females that were present within the forest 250 at least once for a given day thus we were unable to analyze seasonal occupancy data for adult females. 251 All models included animal identity as a random effect to account for potential issues associated with 252 pseudoreplication. All statistical analyses were performed in SAS 9.4 (SAS Institute, Cary, NC, USA) 253 and parameter estimates are presented with $\pm 95 \%$ confidence intervals $(\mathrm{CI})$ or standard errors (SE).

\section{RESULTS}

255 Maternity

We included the microsatellite genotypes of 101 known adults (54 females 47 males) captured 257 within and adjacent to the nest box study sites for maximum-likelihood simulations and to estimate 258 confidence of maternity assignments. The allelic frequencies for each loci were in HWE (Chi-squared 259 test: all $\left.X^{2}<4.41, P>0.11\right)$, with the exception of CB $1\left(X^{2}=13.29, P<0.01\right)$. Therefore, we eliminated 
CB 1 from maternity assignment analyses. We included all 54 females as candidate mothers for radio-

261 tagged juvenile cowbirds. Of the 15 radio-tagged juveniles reared in their natal nest box, we assigned 9

$262(60 \%)$ to a radio-tagged mother for the given year and 2 juveniles to female cowbirds captured in

263 subsequent years. The radio-tagged transplanted juveniles $(n=5)$ were not assigned to any local females.

\section{Forest locations}

We recorded locations for juveniles every 1-2 days (mean $=17 \pm 0.08 \mathrm{SE}$ locations for each

266 individual post-fledging), to determine the effects of age on the distance juveniles travelled from their

267 natal nest. Results from a LMM indicated that juveniles $(n=20)$ were located at greater distances from

268 the fledging nest box with increasing post-fledging age (Fig. 2 ; LMM: $\mathrm{n}=345, \beta=0.13 \pm 0.01 \mathrm{SE}, F_{1,324}$

$269=190.93, P<0.001)$ and we found no difference in mean distance between transplanted $(\mathrm{n}=5)$ and natal

$270 \quad(\mathrm{n}=15)$ juveniles $\left(F_{1,324}=0.61, P=0.44\right)$.

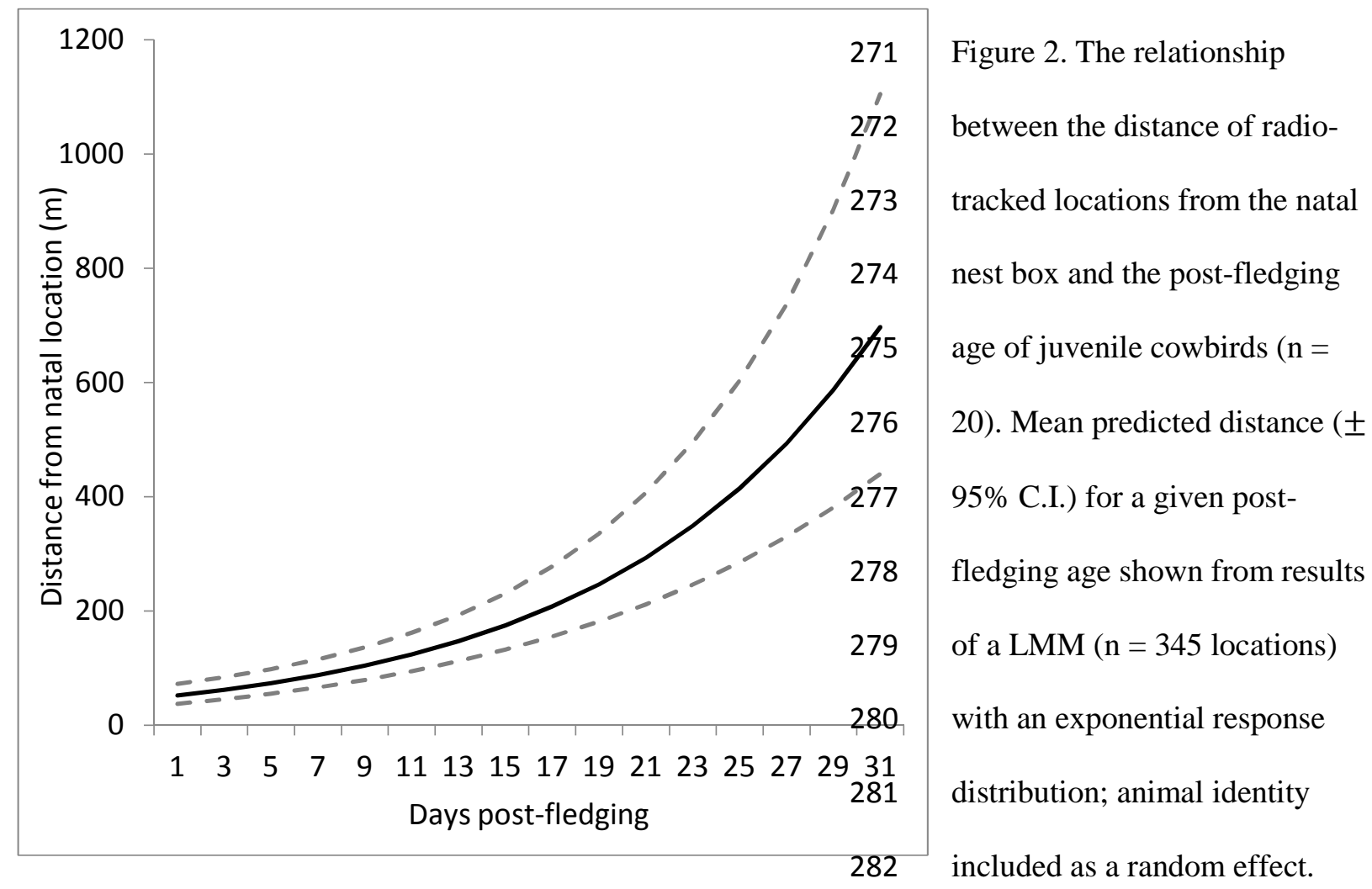

To determine the likelihood that juveniles would come into contact with their genetic mothers, or

284 associated female for transplanted juveniles, we calculated the MCP as an estimate of the home range for

285 each female cowbird. Within the two study sites, we captured and radio-tagged 15 adult females, of which 
3 were radio-tagged in multiple years. One juvenile cowbird was transplanted into an area lacking a radio-

287 tagged female cowbird, and was removed from this analysis. We found that both transplanted juveniles (n $288=4)$ and natal juveniles assigned to a radio-tagged mother $(n=9)$ were more likely to be located outside 289 of the respective female's home-range with increasing post-fledging age (Fig. 3; GLMM: $\mathrm{n}=220 ; \beta=$ $\left.2900.16 \pm 0.03 \mathrm{SE}, F_{1,206}=30.97, P<0.001\right)$ and found no difference between the mean probabilities of

291 being outside the foster/natal nest's female's home-range for transplanted vs. natal juveniles $\left(F_{1,206}=0.05\right.$, $292 P=0.83)$.

293 Figure 3. A comparison between the probability to be located within the maternal, or when transplanted,

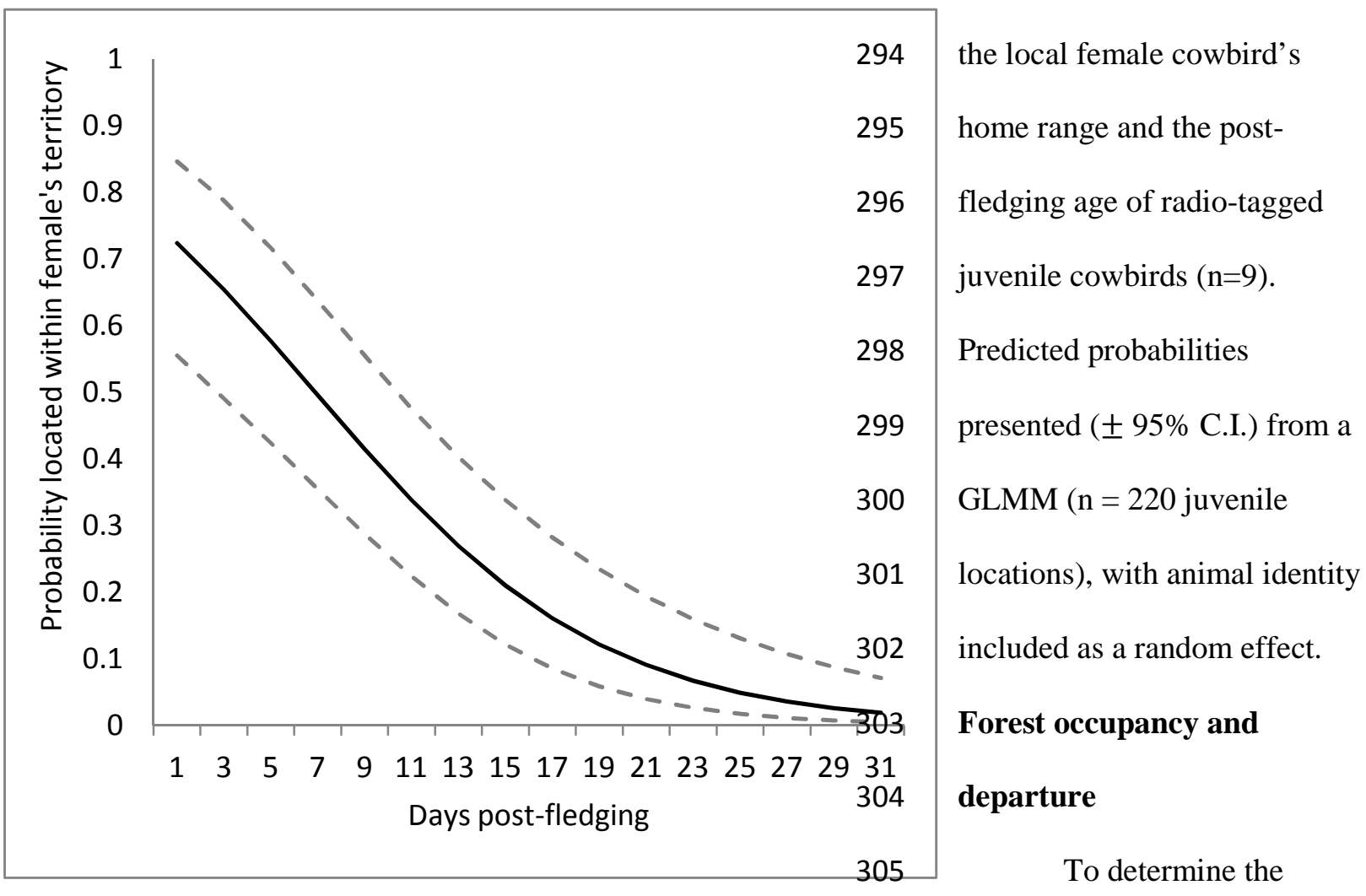

306 probability of forest occupancy and identify departures from the forest, we used data collected from the

307 ARTS during the summers of 2012-2014 within a single study site (HB: Fig. 1) bordered by radio-

308 telemetry towers. The ARTS recorded the signal strength for adult female and juvenile radio frequencies 309 on 516315 occasions with 227665 identified detections (> -130 dBm). Data were binned into 30-minute 310 intervals $(n=23925)$ and the ARTS 'searched' for the given transmitter every $1-2$ minutes $($ mean $=21.2$ 311 times per 30-minute period). By comparing the observations collected via hand-tracking adult and 
312 juvenile cowbirds $(n=327)$, only 3 observations $(1 \%)$ were discordant with the occupancy data; in each 313 case the recorded times may have conflicted between the hand-tracked and ARTS data as occupancy was 314 detected by the ARTS $\sim 10$ minutes after the recorded hand-tracked observation. Therefore, the occupancy 315 estimations derived from the ARTS data appear reliable.

We tracked 10 juveniles with ARTS for the 7296 time intervals, of which, we identified juveniles 317 to be present within the forest on $6718(92 \%)$ intervals. Adult females $(\mathrm{n}=11)$ were present in the forest $31840 \%$ of the 16629 time intervals available for detection. Assuming that a lack of detection for at least 30319 minutes subsequent to being detected represents a departure from the forest, we identified 58 departure events for juvenile cowbirds (range 0-16 per individual). We found that the probability of detecting at 321 least one departure event increased with post-fledging age (Fig. 4; GLMM: $n=163 ; \beta=0.25 \pm 0.04$ SE, $\left.322 F_{1,152}=34.28, P<0.001\right)$ and we did not find a difference between transplanted and natal juveniles $\left(F_{1,152}\right.$ $323=0.17, P=0.83$ ). We found that the probability a juvenile left the forest varied throughout the day (Fig. 5a; GLMM: $\left.\mathrm{n}=787, F_{4,773}=6.55, P<0.001\right)$. Juvenile departures were most likely to occur $(0.11 \pm 0.04$ SE) within 1.5 hours of sunset (18:30-21:30), twice the likelihood of afternoon mean departure probability $(0.05 \pm 0.02 \mathrm{SE})$. The probability of occurrence within the forest for adult female cowbirds 327 varied throughout the day (Fig. 5b; GLMM: $\mathrm{n}=1443, F_{4,1431}=123.12, P<0.001$ ). Yet, we found that the 328 probability of occurrence for adult females to be relatively low $(0.20 \pm 0.04$ SE) within 1.5 hours of sunset, indicating that most juvenile departure events took place when females were unlikely to be present

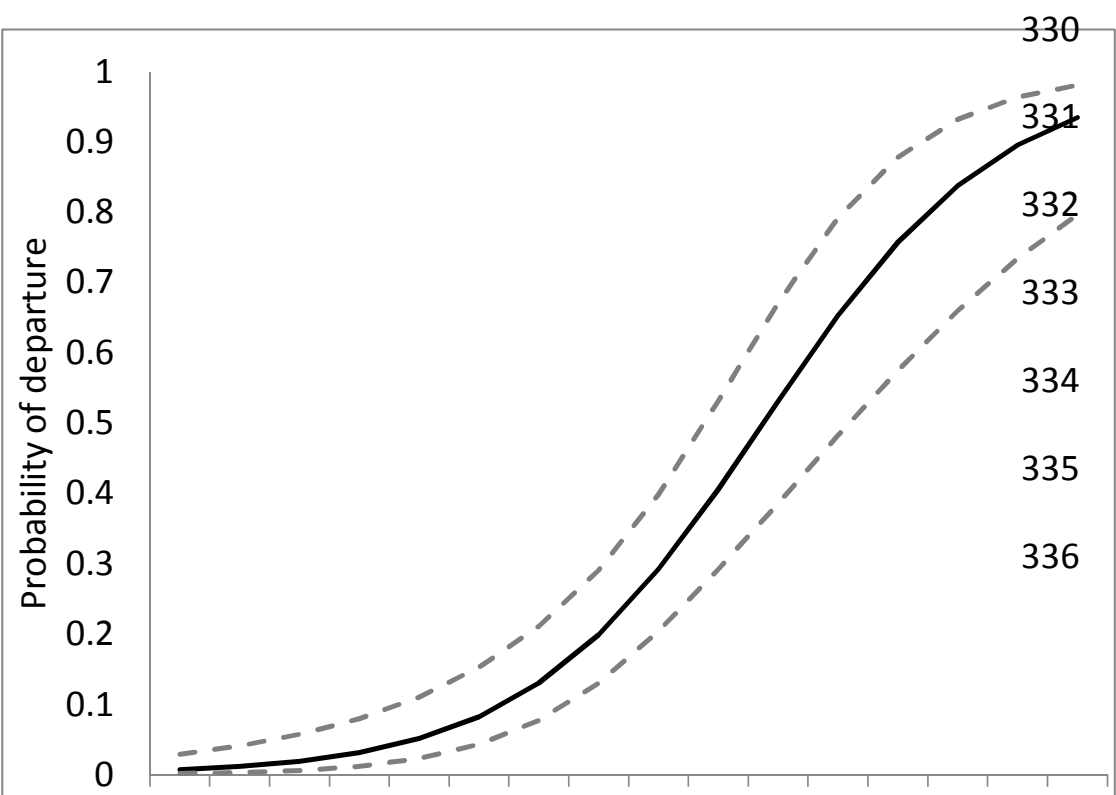
within the forest.

Figure 4. A comparison of the probability of departure (detected by ARTS) and the post-fledging age of radiotagged juvenile cowbirds 
$337(\mathrm{n}=10)$. Predicted probabilities presented $( \pm 95 \%$ C.I. $)$ from a GLMM ( $\mathrm{n}=163$ observation days), with 338 animal identity included as a random effect.

339

340 


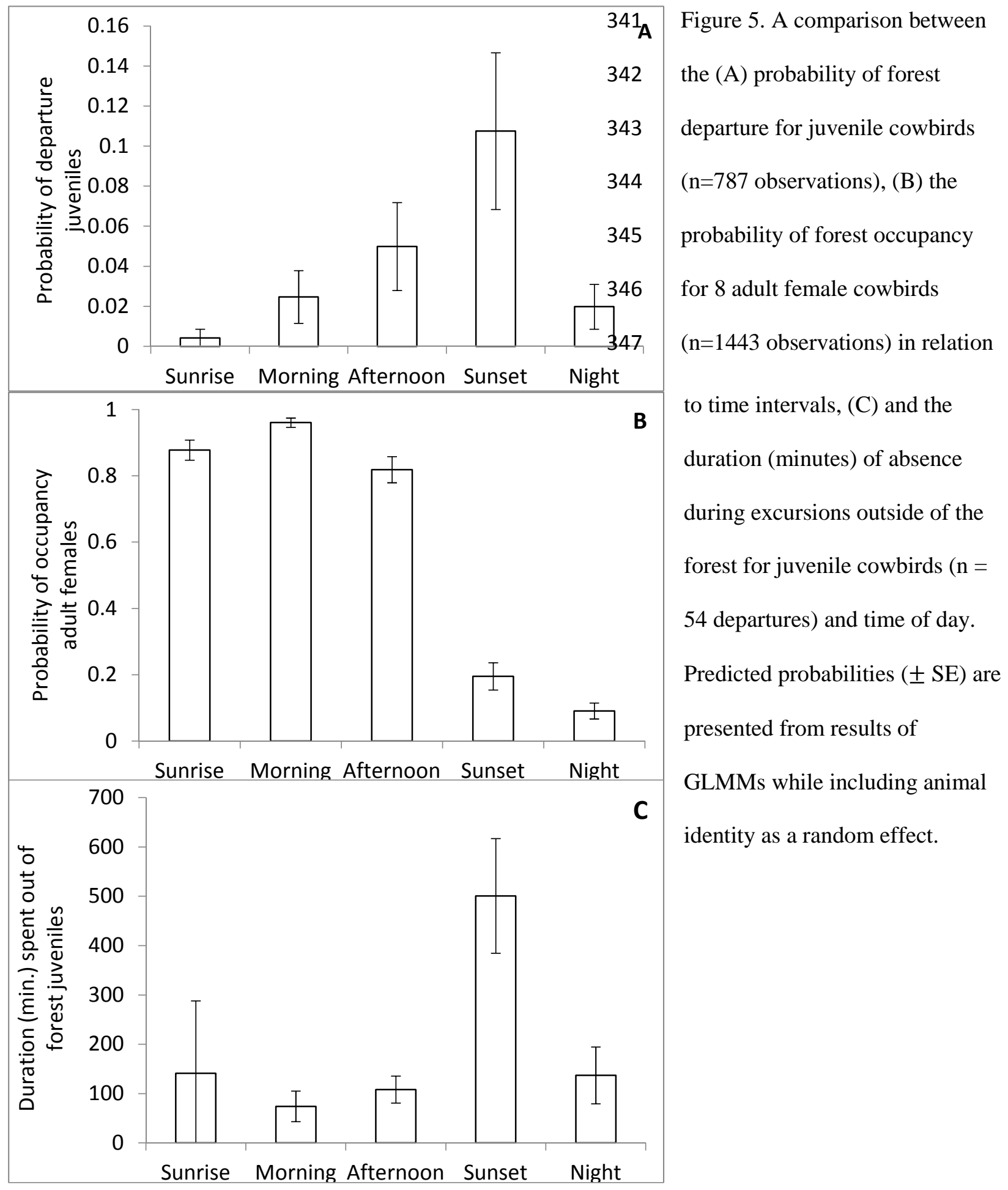

The duration that juveniles were not detected within the forest varied among time periods (Fig.

364 5c; GLMM: $\left.\mathrm{n}=54, F_{4,43}=19.30, P<0.001\right)$, and the average duration was greatest following sunset 365 departure events (500 minutes $\pm 116 \mathrm{SE})$. In concordance with the departure events detected by ARTS, 
we documented 3 radio-tagged juveniles (range 20-30 days post-fledge) departing the forest while hand tracking within 1 hour of sunset. We were able to locate the destination for 2 of these juveniles, each roosting in grassy fields $0.1-0.5 \mathrm{~km}$ from the forest for a total of 7 evenings. On both occasions, we did not observe any warbler host or other cowbirds in proximity to the recently departed juveniles. All 3 juveniles were observed within the forest the following morning, returning near where they left from and

371 receiving parental care from their host. We located two additional radio-tagged juveniles $\sim 1 \mathrm{~km}$ outside

372 of the HB study site during the afternoon, and each subsequently returned to their host parents within the

373 forest; although we were unable to determine if any juvenile or adult cowbirds accompanied the two

374 juveniles during their departures.

\section{Temporal correlation in departure events}

376 Of the 58 juvenile departure events identified by ARTS, 35 (70\%) occurred on days when the assigned 377 radio-tagged mother, or associated female for transplanted juveniles, was detected within the forest. We 378 found a negative correlation between the time of juvenile dispersal and the presence of the associated 379 female cowbird (logistic regression: $\left.\mathrm{n}=35 ; \beta=-0.78 \pm 0.36 \mathrm{SE}, X^{2}=4.39, P=0.03\right)$, with only $14(31 \%)$ juvenile departures occurring at times when the associated female was present within the forest. Indeed,

381 we only detected $4(6.8 \%)$ juvenile departure events occurring during the same 30 -minute interval as 382 when any radio-tagged adult female cowbird was detected departing the forest. We detected 1 juvenile 383 departure event that overlapped with the departure of the genetically assigned mother, yet there were 24 384 minutes separating the specific departure times as determined by raw (i.e. not binned into 30-minute 385 periods) ARTS data. The three additional temporally correlated departure events were those of 386 transplanted juveniles, each coinciding with the departure of radio-tagged female cowbirds whose home387 range did not include the respective transplanted juvenile. Additionally, we identified a single pair of 388 juveniles that departed during the same time interval, each located outside of their respective female's 389 home-range and located back within the forest on the following morning. Although our study design 390 prohibited an accurate estimate for the random co-occurrence of juvenile-female departures, we found 
391 juvenile departures to rarely overlap with any female, and we directly observed juveniles dispersing

392 solitarily; thus, we concluded that simulations to estimate a random expectation would be extraneous.

\section{DISCUSSION}

Contrary to our predictions, we found no support for facilitation by adult female cowbirds being the primary way juvenile cowbirds disperse from their hosts. Juvenile cowbirds typically are not located within their mother's home range when departing the forest and likewise, we detected only one brief (

$39730 \mathrm{~min}$.$) juvenile departure event that temporally overlapped with the departure of the genetically$

398 assigned mother. As observed in some cowbird populations (e.g. Hahn \& Fleischer, 1995; Hauber, 2002;

399 Hauber et al., 2001), female cowbirds in this study were found inhabiting the forest during the post-

400 fledging period of juvenile cowbirds, thus providing the opportunity for juveniles to follow female

401 cowbirds out of the natal habitat to social foraging flocks. Critically, we found no statistical differences

402 between natal and transplanted juveniles' and the local adult females' behaviours in this study, implying a

403 lack of direct kin recognition in parasitic cowbird mothers. The ARTS detection analyses identified only 4

404 (out of 58 total) temporally correlated departures among juveniles and any radio-tagged adult female.

405 Although, an unknown proportion of adult females inhabiting the forest were not radio-tagged, the ARTS

406 system monitored the occupancy of 11 females and $60 \%$ of radio-tagged juveniles were genetically

407 assigned to a radio-tagged female cowbird, indicating that a substantial proportion of females inhabiting

408 the forest were radio-tagged. In some instances, juvenile cowbirds may have followed females without

409 radio-tags, but we think that this is an unlikely explanation for the lack of juvenile departures coinciding

410 with female cowbirds observed in this study. For example, we detected multiple departure events from the

411 forest for most juvenile cowbirds, increasing in probability and duration with age. In particular, we found

412 the greatest probability for juvenile departure near sunset (18:30-21:30), when adult female cowbirds

413 (whether radioed or not) are unlikely to occur within the forest. Visual observations of juvenile cowbirds

414 departing the forest and subsequently roosting solitarily within grasslands provided support for the

415 departure pattern identified by the ARTS data. 
417 host, thereby minimizing the possibility of sexually imprinting on the host species' phenotype. Solitary

418 roosting has been demonstrated to increase with post-fledging age in a few non-parasitic species, such as

419 the mourning dove (Zenaida macroura; Hitchcock \& Mirarchi, 1984) and eastern screech-owl

420 (Megascops asio; Belthoff \& Ritchison, 1990), suggesting its potential importance for achieving

421 independence from parental care and initiating natal dispersal. Juvenile birds are not fed during the night,

422 which decreases their reliance on the natal habitat and (foster) parents. Therefore, departing at sunset may

423 represent an optimal time to initiate exploratory excursions. Our study suggests support for a little

explored alternative to maternally mediated conspecific recognition mechanisms in brood parasites (Hahn

and Fleischer 1995, Hauber 2002): namely genetic predisposition for specific roosting habitats that could induce juvenile cowbirds to depart from the natal habitat, thus initiating the process of independence from the foster parents (as we discuss below).

In addition to promoting spatial segregation from the host, juvenile excursions outside of the forest at sunset may also provide opportunities to locate conspecifics. Experimental manipulations of captive cowbirds have demonstrated that the production and recognition of cowbird song, and the development of appropriate social behaviours, are considerably experience-dependent (Freed-Brown \&

432 White, 2009; King \& West, 1983; O'Loghlen \& Rothstein, 2010; West \& King, 1988). Thus, the rapid 433 discovery and joining of conspecific foraging flocks is critical for appropriate development. Adult 434 cowbirds routinely fly to communal roosts in groups during the evening (Thompson, 1994; pers. obs.), 435 and juvenile cowbirds departing the forest prior to sunset would have the opportunity to locate 436 conspecifics and potentially accompany adult cowbirds to a communal roost. Within the breeding season, 437 brood parasitic Viduidae (Payne, 2010) and Molothrus cowbirds (Ortega, 1998) routinely roost with 438 conspecifics, potentially revealing the importance of communal roosting to the evolution of brood 439 parasitism. Therefore, roosting communally may not only enable individuals to find suitable foraging 440 locations_-'information-center hypothesis' (P. Ward \& Zahavi, 1973; Weatherhead, 1983)—but may also 441 enable juveniles to adopt the songs and behaviours of conspecifics. Although we were unable to hand- 
track any radio-tagged juvenile cowbirds to communal roosts, numerous adult females were observed associating with juveniles (all without radio-tags) at a communal roost during July 2014 (pers. obs.),

444 indicating that departing at sunset may play a role in the juvenile cowbird's ability to locate conspecifics.

Post-fledging birds typically disperse to specific habitat types, often dissimilar to breeding

447 promote the prevalence of conspecific interactions if habitat selection is largely innate (e.g. Grosch, 2004;

448 Partridge, 1974), and shared among juvenile cowbirds and adults. Upon interaction with conspecifics

449 within this habitat (e.g. grass pasture), genetically guided preferences for conspecific vocalizations (i.e.

450 "passwords"; Hauber et al., 2001) and learned components such as self-referent phenotype matching

451 (Hauber, Sherman, \& Paprika, 2000) would facilitate conspecific recognition and subsequently enable the

452 acquisition of appropriate behaviours. Although juveniles cowbirds are unlikely to follow adult females to

453 foraging areas (this study), related juvenile-adult pairings could occur at a non-negligible baseline rate in

454 specific habitat configurations and at specific local densities of cowbirds, as found by Hahn and Fleischer

455 (1995) in upstate New York's fragmented landscape. Under this scenario, juveniles would disperse out of

456 their natal area (alone) and locate a conspecific foraging flock—with the probability that the flock

457 contains the genetic mother related to the number of accessible foraging flocks, the distance to foraging

458 flock and the density of local cowbirds.

Spatial segregation from hosts may be an important process in the development of juvenile brood parasites and the origin of brood parasitism. As in most cross-fostering experiments (ten Cate \& Vos,

461 1999), captive juvenile brood parasites will sexually imprint on their host's phenotype when the

462 associations are extended beyond the typical timeframe observed in nature (Freeberg et al., 1995;

463 Sorenson et al., 2010). The redhead, an interspecific parasitic duck, primarily migrates to different

464 wintering habitats than its host, which may enable parasitic offspring to avoid imprinting or reverse

465 preferences acquired from interactions with the host (Sorenson et al., 2010). In support of this hypothesis,

466 the lack of sexual imprinting observed in non-parasitic, but experimentally cross-fostered pied flycatchers

467 (Ficedula hypoleuca), may reflect the flycatcher's migratory behaviour and resultant limitation of social 
interactions with experimental foster species (Slagsvold, Hansen, Johannessen, \& Lifjeld, 2002). While

469 segregation behaviours of juvenile brood parasites may reduce the likelihood of misimprinting on host's

470 phenotype, it does not explain how juvenile brood parasites locate and recognize conspecifics. Genetic

471 predispositions for habitat and phenotypic characteristics shared among conspecifics, in combination with

472 cues learned from social interactions and self-inspection, are all likely involved with obligate parasite's

473 species recognition ontogeny (Göth \& Hauber, 2004; this study). Furthermore, selection has likely

474 favored other mechanisms, such as delayed onsets or password-triggered flexibility in the sensitive

475 periods of brood parasite offspring and future research investigating these factors will help increase our

476 understanding of the origins and evolution of brood parasitism and its complex impact on social

477 recognition and ontogeny.

478 LITERATURE CITED

479 Alderson, G. W., Gibbs, H. L., \& Sealy, S. G. (1999). Determining the reproductive behaviour of individual brown-headed cowbirds using microsatellite DNA markers. Animal Behaviour, 58(4), 895-905. doi: 10.1006/anbe.1999.1220

Bateson, P. (1979). How do sensitive periods arise and what are they for? Animal Behaviour, 27, 470486.

Belthoff, J. R., \& Ritchison, G. (1990). Roosting behavior of postfledging eastern screech-owls. The Auk, 107(3), 567-579. doi: 10.2307/4087921

Bolker, B. M., Brooks, M. E., Clark, C. J., Geange, S. W., Poulsen, J. R., Stevens, M. H. H., \& White, J. S. S. (2009). Generalized linear mixed models: a practical guide for ecology and evolution. Trends in Ecology \& Evolution, 24(3), 127-135. doi: 10.1016/j.tree.2008.10.008

Brainard, M. S., \& Doupe, A. J. (2002). What songbirds teach us about learning. Nature, 417(6886), 351358.

Cox, W. A., Thompson, F. R., Cox, A. S., \& Faaborg, J. (2014). Post-fledging survival in passerine birds and the value of post-fledging studies to conservation. The Journal of Wildlife Management, 78(2), 183-193. doi: 10.1002/jwmg.670 
Davies, N. B. (2000). Cuckoo, cowbirds and other cheats. London: T. \& A. Poyser.

Dufty, A. M. (1982). Movements and activities of radio-tracked brown-headed cowbirds. Auk, 99(2), 316327.

Feeney, W. E., Welbergen, J. A., \& Langmore, N. E. (2014). Advances in the study of coevolution between avian brood parasites and their hosts. Annual Review of Ecology, Evolution, and Systematics, 45, 227-246. doi: 10.1146/annurev-ecolsys-120213-091603

Freeberg, T. M., King, A. P., \& West, M. J. (1995). Social malleability in cowbirds (Molothrus ater artemisiae): species and mate recognition in the first 2 years of life. Journal of Comparative Psychology, 109(4), 357-367. doi: 10.1037/0735-7036.109.4.357

Freed-Brown, G., \& White, D. J. (2009). Acoustic mate copying: female cowbirds attend to other females' vocalizations to modify their song preferences. Proceedings of the Royal Society B: Biological Sciences, 276(1671), 3319-3325. doi: 10.1098/rspb.2009.0580

Göth, A., \& Hauber, M. E. (2004). Ecological approaches to species recognition in birds through studies of model and non-model species. Annales Zoologici Fennici, 41(6), 823-842.

Grosch, K. (2004). Hybridization between redstart Phoenicurus phoenicurus and black redstart $P$. ochruros, and the effect on habitat exploitation. Journal of Avian Biology, 35(3), 217-223. doi: 10.1111/j.0908-8857.2004.03128.x

Hahn, D. C., \& Fleischer, R. C. (1995). DNA fingerprint similarity between female and juvenile brownheaded cowbirds trapped together. Animal Behaviour, 49(6), 1577-1580.

Hahn, D. C., \& Hatfield, J. S. (1995). Parasitism at the landscape scale: cowbirds prefer forests. Conservation Biology, 9(6), 1415-1424. doi: 10.1046/j.1523-1739.1995.09061415.x

Hahn, D. C., Sedgwick, J. A., Painter, I. S., \& Casna, N. J. (1999). A spatial and genetic analysis of cowbird host selection. In M. L. Morrison, L. S. Hall, S. K. Robinson, S. I. Rothstein, D. C. Hahn \& T. D. Rich (Eds.), Research and management of the brown-headed cowbird in western landscapes (Vol. 18, pp. 204-217). 
Hauber, M. E. (2001). Site selection and repeatability in brown-headed cowbird (Molothrus ater) parasitism of eastern phoebe (Sayornis phoebe) nests. Canadian Journal of Zoology, 79(8), 15181523. doi: 10.1139/z01-091

Hauber, M. E. (2002). First contact: a role for adult-offspring social association in the species recognition system of brood parasites. Annales Zoologici Fennici, 39(4), 291-305.

Hauber, M. E., \& Dearborn, D. C. (2003). Parentage without parental care: what to look for in genetic studies of obligate brood-parasitic mating systems. Auk, 120(1), 1-13.

Hauber, M. E., Russo, S. A., \& Sherman, P. W. (2001). A password for species recognition in a broodparasitic bird. Proceedings of the Royal Society B-Biological Sciences, 268(1471), 1041-1048.

Hauber, M. E., Sherman, P. W., \& Paprika, D. (2000). Self-referent phenotype matching in a brood parasite: the armpit effect in brown-headed cowbirds (Molothrus ater). Animal Cognition, 3(2), 113-117. doi: 10.1007/s100710000071

Hauber, M. E., Strausberger, B. M., Feldheim, K. A., Lock, J., \& Cassey, P. (2012). Indirect estimates of breeding and natal philopatry in an obligate avian brood parasite. Journal of Ornithology, 153(2), 467-475. doi: 10.1007/s10336-011-0762-6

Hensch, T. K. (2004). Critical period regulation. Annual Review of Neuroscience, 27, 549-579.

Hitchcock, R. R., \& Mirarchi, R. E. (1984). Duration of dependence of wild fledgling mourning doves upon parental care. The Journal of Wildlife Management, 48(1), 99-108. doi: 10.2307/3808457

Hoover, J. P. (2003). Multiple effects of brood parasitism reduce the reproductive success of prothonotary warblers, Protonotaria citrea. Animal Behaviour, 65, 923-934. doi: 10.1006/anbe.2003.2155

Hoover, J. P., \& Hauber, M. E. (2007). Individual patterns of habitat and nest-site use by hosts promote transgenerational transmission of avian brood parasitism status. Journal of Animal Ecology, 76(6), 1208-1214. doi: 10.1111/j.1365-2656.2007.01291.x

Hoover, J. P., Yasukawa, K., \& Hauber, M. E. (2006). Spatially and temporally structured avian brood parasitism affects the fitness benefits of hosts' rejection strategies. Animal Behaviour, 72, 881890. doi: 10.1016/j.anbehav.2006.02.011 
Hoover, J. P., \& Robinson, S. K. (2007). Retaliatory mafia behavior by a parasitic cowbird favors host acceptance of parasitic eggs. Proceedings of the National Academy of Sciences, 104(11), 44794483. doi: 10.1073/pnas.0609710104

Irwin, D. E., \& Price, T. (1999). Sexual imprinting, learning and speciation. Heredity, 82(4), 347-354. doi: $10.1038 /$ sj.hdy.6885270

Kalinowski, S. T., Taper, M. L., \& Marshall, T. C. (2007). Revising how the computer program cervus accommodates genotyping error increases success in paternity assignment. Molecular Ecology, 16(5), 1099-1106. doi: 10.1111/j.1365-294X.2007.03089.x

Kays, R., Tilak, S., Crofoot, M., Fountain, T., Obando, D., Ortega, A., .. . Wikelski, M. (2011). Tracking animal location and activity with an automated radio telemetry system in a tropical rainforest. The Computer Journal, 54(12), 1931-1948. doi: 10.1093/comjn1/bxr072

King, A. P., \& West, M. J. (1977). Species identification in the North American cowbird: appropriate responses to abnormal song. Science, 195(4282), 1002-1004. doi: 10.1126/science.841321

King, A. P., \& West, M. J. (1983). Epigenesis of cowbird song—a joint endeavour of males and females. Nature, 305(5936), 704-706.

Kruger, O. (2007). Cuckoos, cowbirds and hosts: adaptations, trade-offs and constraints. Philosophical Transactions of the Royal Society B-Biological Sciences, 362(1486), 1873-1886. doi: 10.1098/rstb.2006.1849

Laland, K. N. (1994). On the evolutionary consequences of sexual imprinting. Evolution, 48(2), 477-489.

Longmire, J. L., Roach, J. L., Maltbie, M., White, P. S., Tatum, O. L., Makova, K. D., \& Hahn, D. C. (2001). Tetranucleotide microsatellite markers for the brown-headed cowbird Molothrus ater. Journal of Avian Biology, 32(1), 76-78. doi: 10.1034/j.1600-048X.2001.320111.x

Lowther, P. E. (1993). Brown-headed cowbird (Molothrus ater). In A. Poole, Gill, F. (Ed.), The Birds of North America. Ithaca: Cornell Lab of Ornithology. 
McLaren, C. M., Woolfenden, B. E., Gibbs, H. L. \& Sealy, S. G. (2003). Temporal patterns of multiple parasitism by brown-headed cowbirds (Molothrus ater) on song sparrows (Melospiza melodia). Canadian Journal of Zoology, 81(2), 281-286.

O'Loghlen, A. L., \& Rothstein, S. I. (2010). Delayed sensory learning and development of dialect songs in brown-headed cowbirds, Molothrus ater. Animal Behaviour, 79(2), 299-311. doi: 10.1016/j.anbehav.2009.10.029

Ortega, C. P. (1998). Cowbirds and other brood parasites: University of Arizona Press.

Partridge, L. (1974). Habitat selection in titmice. Nature, 247(5442), 573-574. doi: 10.1038/247573a0

Payne, R. B. (1977). The ecology of brood parasitism in birds. Annual Review of Ecology and Systematics, 1-28. doi: 10.1146/annurev.es.08.110177.000245

Payne, R. B. (2010). Viduidae (whydahs and indigobirds). In J. Del Hoyo, A. Elliot \& D. Christie (Eds.), Handbook of the birds of the world (Vol. 15, pp. 198-232). Barcelona: Lynx edicions.

Payne, R. B., Payne, L. L., Woods, J. L., \& Sorenson, M. D. (2000). Imprinting and the origin of parasitehost species associations in brood-parasitic indigobirds, Vidua chalybeata. Animal Behaviour, 59(1), 69-81. doi: 10.1006/anbe.1999.1283

Payne, R. B., \& Sorenson, M. D. (2004). Behavioral and genetic identification of a hybrid vidua: Maternal origin and mate choice in a brood-parasitic finch. The Auk, 121(1), 156-161. doi: $10.2307 / 4090064$

Petit, L. J. (1999). Prothonotary warbler, Prothonotaria citrea. In A. Poole, Gill, F. (Ed.), The Birds of North America (Vol. 408). Ithaca: Cornell Lab of Ornithology.

Powell, R. A. (2000). Animal home ranges and territories and home range estimators. In L. Boitani \& T. K. Fuller (Eds.), Research techniques in animal ecology: controversies and consequences (pp. 65-110). New York: Columbia University Press.

Price, T. (2008). Speciation in birds. Greenwood Village, CO: Roberts and Company

Raim, A. (2000). Spatial patterns of breeding female brown-headed cowbirds on an Illinois site. In J. N. M. Smith, T. L. Cook, S. I. Rothstein, S. K. Robinson \& S. G. Sealy (Eds.), Ecology and 
management of cowbirds and their hosts: studies in the conservation of North American passerine birds. (pp. 87-99): University of Texas Press.

Rappole, J. H., \& Tipton, A. R. (1991). New harness design for attachment of radio transmitters to small passerines. Journal of Field Ornithology, 62(3), 335-337. doi: 10.2307/20065798

Rivers, J. W., Young, S., Gonzalez, E. G., Horton, B., Lock, J., \& Fleischer, R. C. (2012). High levels of relatedness between brown-headed cowbird (Molothrus ater) nestmates in a heavily parasitized host community. The Auk, 129(4), 623-631.

Rothstein, S. I. (1990). A model system for coevolution: avian brood parasitism. Annual Review of Ecology and Systematics, 21, 481-508. doi: 10.1146/annurev.ecolsys.21.1.481

Rousset, F. (2008). genepop'007: a complete re-implementation of the genepop software for Windows and Linux. Molecular Ecology Resources, 8(1), 103-106. doi: 10.1111/j.1471-8286.2007.01931.x

Slagsvold, T., \& Hansen, B. T. (2001). Sexual imprinting and the origin of obligate brood parasitism in birds. American Naturalist, 158(4), 354-367. doi: 10.1086/321994

Slagsvold, T., Hansen, B. T., Johannessen, L. E., \& Lifjeld, J. T. (2002). Mate choice and imprinting in birds studied by cross-fostering in the wild. Proceedings of the Royal Society of London Series BBiological Sciences, 269(1499), 1449-1455. doi: 10.1098/rspb.2002.2045

Soler, M. (2014). Long-term coevolution between avian brood parasites and their hosts. Biological Reviews, 89(3), 688-704. doi: 10.1111/brv.12075

Soler, M., \& Soler, J. J. (1999). Innate versus learned recognition of conspecifics in great spotted cuckoos Clamator glandarius. Animal Cognition, 2(2), 97-102. doi: 10.1007/s100710050029

Sorenson, M. D., Hauber, M. E., \& Derrickson, S. R. (2010). Sexual imprinting misguides species recognition in a facultative interspecific brood parasite. Proceedings of the Royal Society BBiological Sciences, 277(1697), 3079-3085. doi: 10.1098/rspb.2010.0592

Strausberger, B. M., \& Ashley, M. V. (2001). Eggs yield nuclear DNA from egg-laying female cowbirds, their embryos and offspring. Conservation Genetics, 2(4), 385-390. doi:

10.1023/A: 1012526315617 
621 Strausberger, B. M., \& Ashley, M. V. (2003). Breeding biology of brood parasitic brown-headed

622

623

624

625

626

627

628

629

630

631

632

633

634

635

636

637

638

639

640

641

642

643

644

645

cowbirds (Molothrus ater) characterized by parent-offspring and sibling-group reconstruction.

The Auk, 120(2), 433-445. doi: 10.1642/0004-8038(2003)120[0433:BBOBPB]2.0.CO;2

Streby, H. M., Peterson, S. M., \& Kapfer, P. M. (2009). Fledging success is a poor indicator of the effects of bird blow flies on Ovenbird survival. Condor, 111(1), 193-197. doi:

10.1525/cond.2009.080095

Streby, H. M., McAllister, T. L., Peterson, S. M., Kramer, G. R., Lehman, J. A., \& Andersen, D. E. (2015). Minimizing marker mass and handling time when attaching radio-transmitters and geolocators to small songbirds. Condor, 117(2) 249-255. doi: 10.1650/CONDOR-14-182.1

ten Cate, C., \& Vos, D. R. (1999). Sexual imprinting and evolutionary processes in birds: a reassessment. Advances in the Study of Behavior, 28, 1-31.

Thompson, F. R. (1994). Temporal and spatial patterns of breeding brown-headed cowbirds in the Midwestern United States. Auk, 111(4), 979-990.

Ward, M. P., Alessi, M., Benson, T. J., \& Chiavacci, S. J. (2014). The active nightlife of diurnal birds: extraterritorial forays and nocturnal activity patterns. Animal Behaviour, 88(0), 175-184. doi: 10.1016/j.anbehav.2013.11.024

Ward, M. P., Sperry, J. H., \& Weatherhead, P. J. (2013). Evaluation of automated radio telemetry for quantifying movements and home ranges of snakes. Journal of Herpetology, 47(2), 337-345. doi: $10.1670 / 12-018$

Ward, P., \& Zahavi, A. (1973). The importance of certain assemblages of birds as "information-centres" for food-finding. Ibis, 115(4), 517-534. doi: 10.1111/j.1474-919X.1973.tb01990.x

Weatherhead, P. J. (1983). Two principal strategies in avian communal roosts. The American Naturalist, 121(2), 237-243. doi: 10.2307/2461125

West, M. J., \& King, A. P. (1988). Female visual displays affect the development of male song in the cowbird. Nature, 334(6179), 244-246. 
646 Woodward, P. W. (1983). Behavioral ecology of fledgling brown-headed cowbirds and their hosts. Condor, 85(2), 151-163.

648 Yom-Tov, Y., \& Geffen, E. (2006). On the origin of brood parasitism in altricial birds. Behavioral 649 Ecology, 17(2), 196-205. doi: 10.1093/beheco/arj013

650

651 


\section{ACKNOWLEDGEMENTS}

We thank V. Kichline, A. Albores, C. Buerke, C. Carreau, and J. York, for help collecting cowbird data and S. Chiavacchi and A. Celis-Murillo for their help with constructing the ARTS. Our manuscript was greatly improved by the comments from A. Suarez, R. Schooley and two anonymous reviewers. The staff from the Illinois Natural History Survey, Cypress Creek National Wildlife Refuge and Cache River State Natural Area provided logistical support. Financial support was provided by the United States Fish and Wildlife Service (INT 1448-0003-95-1007), The Nature Conservancy, the Illinois Department of Natural Resources Wildlife Preservation Fund, the University of Illinois, the Animal Behavior Society, the American Ornithologists' Union, and the University of Illinois. During the analysis and writing, MML and MEH were supported by NSF/IOS grant: 1456524 . 


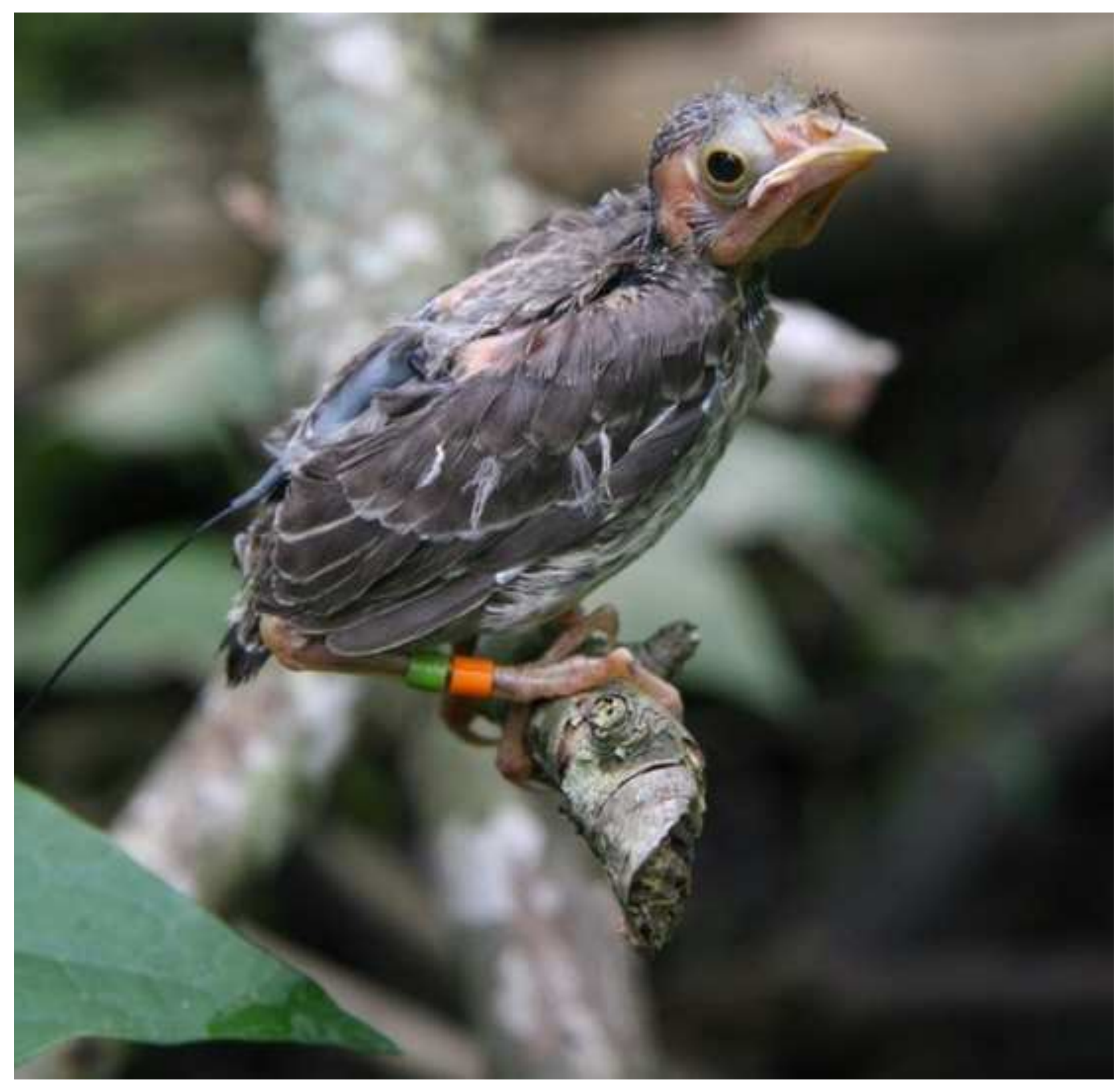

